\title{
Editorial
}

\section{Editorial for the special issue on Middle East derivatives}

Journal of Derivatives \& Hedge Funds (2008) 14, 159. doi:10.1057/jdhf.2008.20

Risks are managed with a variety of straightforward techniques, including match funding and selective use of derivatives. The use of derivatives to mitigate or eliminate certain financial and market risks can be conducted by businesses in diverse markets around the world; and local funding is not always efficient. The derivative must be highly effective in offsetting either changes in fair value or cash flows, as appropriate, for the risk being hedged.

Derivatives have proven to be useful in most Middle Eastern countries, especially in the petroleum and natural gas industrial countries. They would probably be used more extensively if financial and market data were more transparent. Managers may limit derivative use, because their presence in company accounts is troubling to some classes of investors.

As energy markets and companies expanded their role from being just producers and distributors to being energy traders as well, they found increased opportunities for using derivatives for earnings management. The main reason for this development is the accounting requirement of mark-to-market accounting for derivatives. The applications of derivatives to risk management are limited by the availability of spot market data - specifically, timely, public and accurate information on prices and quantities.
We are publishing eight papers on broad topics concerning emerging markets, one discussing the influence of the banking sector on stock exchange and the reasons for the lack of interest in merger and acquisition in contrast to the general trend in banking industry worldwide. Other papers discuss foreign exchange risk management techniques such as the financial derivatives, banking sector role in the development of risk management. Two papers investigate the effect of the electronic trading system on market volatility and liquidity before and after its implementation. The GARCH model is still used to test the volatility level in many markets. The papers discuss the stability of the Middle East stock markets as expressed by volatility of trading volume, and their association with the volatility of stock prices, which became a new phenomenon attached to the trading environment in the region stock markets. Other papers test the extent to which war and terrorism have produced an impact on the Middle East financial markets risk, especially Sovereign risk. Credit rating agencies such as Moody's and Standard and Poor's have revised their ratings to minimise risk in such an unstable region.

\section{Naser Ibrahim Abumustafa}

Guest Editor 